\title{
Elements of Good Change Leadership in the Post-Pandemic Economy
}

\author{
Mostafa Sayyadi
}

\begin{abstract}
The purpose of this article is to indicate the importance of leadership in the postpandemic recovery. The design of this article, which is based on my interviews with 48 consultants, is structured to offer a framework that influences the linkages among organizational leadership, knowledge management, organizational resources, and postpandemic recovery. This article presents a framework that can guide executives in a post-pandemic world. This article also uncovers that the crucial role of knowledge management activities, such as coordinating and hosting the continuous sessions of company-wide experts to share their knowledge, may be underestimated and underutilized in a post-pandemic world.
\end{abstract}




\section{Introduction}

In a post-pandemic world, knowledge is shared via Zoom, WebEx, and internal communication systems. Accordingly, remote work has risen as the most predominant concern along with keeping stakeholders safe during the pandemic. The post-pandemic recovery has created hybrid leadership models that incorporate both in-office and remote communication. Electronic meetings have been also introduced as real-time think tanks that have exploited knowledge management as the world recovers from the pandemic. The importance of organizational resources is also escalated in the postpandemic recovery. They have led to a new look at resilience as organizations recovery from COVID-19. In this article, I explain the better use of organizational resources to formulate a vision of knowledge management improvement for the post-pandemic recovery.

\section{Discussions}

Leaders are those executives who influence subordinates through building and sustaining relationships with them (Avolio, Waldman \& Yammarino, 1991; Canty, 2005). Knowledge management is a set of processes aimed at creating value through generating and applying intellectual capital (Marr, et al., 2003). By reviewing interviews with 48 American management consultants, this article provides arguments on the mediating effects of organizational resources (i.e. culture, structure, and strategy) in the relationship between organizational leadership and knowledge management.

These three organizational resources cannot make or break an organization but incorporating each of them together can begin to move an organization to COVID-19 recovery. 48 American management consultants I contacted told me that they are focusing on the role of change leadership. This research establishes a framework to address the following questions:

- How does leadership indirectly impact knowledge management?

- How can the better use of these organizational resources mediate the relationship between leadership and knowledge management?

\section{The Mediating Role of Culture}

Culture is projected to include three dimensions of collaboration, trust, and learning (Neeley, 2021). In terms of the cultural aspect of trust, consultants noted that "leaders should enhance trust-based relationships". Trust-based relationships are ideal for sharing tacit knowledge (Wenger, 1998). This is not a novel issue and has surfaced as a scholarly idea for decades. It simply has more applicability today as we survive the pandemic and prepare for the post-pandemic. In fact, leaders' ability to create knowledge and develop a more innovative climate is a product of employees' trust in their leaders' decisions. For example, consultants expressed that "with new and reborn technology, trusting a system that is secure with modern technology will help executives lead now and in the future". Executives that employ leadership can engender trust by focusing on identifying employees' individual needs within companies. 
Furthermore, collaboration is a necessary precursor to creating new ideas and knowledge (Wenger, 1998). Most consultants agreed with the current assumptions found in the business literature that leaders provide the freedom for employees in order to explore new ideas and knowledge (Horwitz, et al., 2008; Patiar \& Mia, 2009). They noted that "giving people platform space and presentation time is an effective use of time and resources because culture when used as an internal resource, can positively influence competitive advantage through developing collaboration". In addition, sharing best practices and experiences (i.e. learning, technology, and presentation equipment) could play a crucial role in embedding organizational knowledge in members and creating new knowledge for companies for the post-COVID-19 recovery (Chatman \& Gino, 2020). Thus, firms emphasizing the three cultural aspects of trust, collaboration, and learning are much stronger in generating new ideas and knowledge.

\section{The Mediating Role of Structure}

Leaders achieve a higher degree of effectiveness in a decentralized structure (Jung et al., 2008). This was confirmed in my interviews with consultants. For example, they mentioned that "an executive acting as a leader develops decentralized structures with the aim of improving knowledge sharing and creating a more innovative climate". Moreover, leaders need to aggregate human capital as social capital to implement change to create valuable new resources for the organization as a whole (GarciaMorales et al., 2012). In fact, highly centralized structures are more bureaucratic, and this, as noted by interviewed consultants themselves, negatively contributes to the effectiveness of leadership in changing existing situations. Particularly, they mentioned that "decentralization encourages organizational communications, and consequently develops a climate of openness for employees to exchange their new ideas".

Also, consultants noted that "delegation of decision-making power could create a climate that in turn develops inter-departmental communication within organizations." In the remote setting, this was done via email communication, instant messenger, and text. Pre-meeting and post-meeting communication was enhanced with this technology. Thereafter, once the information and clarification are disseminated, then the employees can implement ideas through the delegated authority of decision-making to their departments to the lowest levels possible and still keep successful execution (Cardinal, 2001; Sivadas \& Dwyer, 2000).

\section{The Mediating Role of Strategy}

Scholars found that organizational strategy is theorized to encompass four dimensions, including analysis, defensiveness, futurity, and pro-activeness (Bergeron et al., 2004). Analysis strategy stimulates organizations to use information systems in their decisionmaking processes that lead to an analysis of problems and making correct decisions, it also leads to creating innovative ideas to solve problems (Zheng, Yang \& McLean 2010). Consultants agreed that leaders apply an analysis strategy to provide new and innovative solutions for organizational problems. The point was emphasized with operational risk management. Financial risk management illuminated but the operational risk superseded as organizations struggled for survival. Focusing on the post-pandemic, leaders need to develop a futurity strategy to develop a more 
comprehensive vision for the future. Consultants also noted that "a futurity strategy could also promote the knowledge utilization process by providing a series of clear guidelines for companies to track future trends in the business environment, and accordingly conduct "what-if" analysis and allocate organizational resources". In addition, leaders need to apply a defensive strategy to implement the required modifications in order to efficiently use organizational resources, decrease costs, and control the resources (Venkatraman, 1989). Furthermore, they should take proactiveness and futurity strategies to inspire employees to investigate better solutions and opportunities (Akman \& Yilmaz, 2008). Therefore, leaders positively contribute to pro-activeness and futurity strategies by setting high expectations and providing a suitable situation for followers to identify new opportunities. These four tenets of strategic initiatives were predominant today.

Consultants also agreed that an analysis strategy could play a critical role in accumulating organizational knowledge, including both processes of knowledge creation and acquisition. In addition, consultants all agreed that a pro-active strategy could positively contribute to knowledge management performance through developing interactions with external environments. With the pandemic in its highest stage of completion, executives realize that effective implementation of knowledge management projects requires a continuous investigation from external business environments. A defensiveness approach enhances efficiency through reusing knowledge to reduce organizational costs (Zheng, Yang \& Mclean, 2010). In the post-pandemic, consultants also agreed that a futurity strategy could promote the process of knowledge application by providing a series of guidelines for companies, aiming at tracking trends, conducting "what-if" analysis, allocating capabilities, and adapting actions. For example, consultants mentioned that "using a futurity strategy worked together with Human Resources to save as many jobs as they can in such a turbulent environment and that one of the parameters that helped was that many people selected early retirement, leaving a gap in attrition levels".

\section{Conclusions}

This article offers several implications for practice as we work through the pandemic of COVID-19. This article highlights the vital importance of leadership to stimulate a culture of learning as many followers are working remotely, builds upon collaboration, and provides for an equal amount of trust for both leaders and their remote workers. The workforce that was once in house is now working remotely and this impacts the organizational structure now and in the future and there is a vast need to improve strategies within organizations. 


\section{References}

Akman, G., \& Yilmaz C. (2008). Innovative Capability, Innovation Strategy and Market Orientation: An Empirical Analysis in Turkish Software Industry. International Journal of Innovation Management, 12(1), 69-111.

Avolio, B.J., Waldman, D.A., \& Yammarino, F.J. (1991). Leading in the 1990s: the four I's of transformational leadership. Journal of European Industrial Training, 15(4), 9-16.

Bergeron, F., Raymond, L., \& Rivard, S. (2004). Ideal patterns of strategic alignment and business performance. Information \& management, 41 (8), 1003-1020.

Canty, L.T. (2005). Conceptual assessment: transformational, transactional and laissezfaire leadership styles and job performances of managers as perceived by their direct reports [Unpublished doctoral dissertation]. Capella University.

Cardinal, L.B. (2001). Technological innovation in the pharmaceutical industry: the use of organizational control in managing research and development. Organization Science, $12(1), 19-36$.

Chatman,J., \& Gino, F. (2000). Don't Let the Pandemic Sink Your Company Culture. Harvrad Business Review (August, 2020).

García-Morales, V.J., Jiménez-Barrionuevo, M.M., \& Gutiérrez-Gutiérrez, L. (2012). Transformational leadership influence on organizational performance through organizational learning and innovation. Journal of Business Research, 65(7), 10401050 .

Horwitz, I.B., Horwitz, S.K., Daram, P., Brandt, M.L., Brunicardi, F.C., \& Awad, S.S. (2008). Transformational, transactional, and passive-avoidant leadership characteristics of a surgical resident cohort: analysis using the multifactor leadership questionnaire and implications for improving surgical education curriculums. The Journal of surgical research, 148(1), 49-59.

Jung, D., Wu, A., \& Chow, C.W. (2008). Towards understanding the direct and indirect effects of CEOs' transformational leadership on firm innovation. The Leadership Quarterly, 19(5), 582-594.

Marr, B., Gupta, O., Roos, G., \& Pike, S. (2003). Intellectual capital and knowledge management effectiveness. Management Decision, 41(8), 771-781.

Neeley, T . (2021). Remote Work Revolution: Succeeding from Anywhere. New York: HarperCollins Publishers LLC.

Patiar, A., \& Mia, L. (2009). Transformational leadership style, market competition and departmental performance: Evidence from luxury hotels in Australia. International Journal of Hospitality Management, 28(2), 254-262. 
Sivadas, E., \& Dwyer, F.R. (2000). An examination of organizational factors influencing new product success in internal and alliance based processes. Journal of Marketing, 64(1), 31-50.

Venkatraman, N. (1989). Strategic orientation of business enterprises: the construct, dimensionality, and measurement. Management Science, 35(8), 942-962.

Wenger, E.C. (1998). Communities of practice. London: Cambridge University Press.

Zheng, W., Yang, B., \& Mclean, G.N. (2010). Linking organizational culture, structure, strategy, and organizational effectiveness: mediating role of knowledge management. Journal of Business Research, 63(7), 763-771. 